\section{Dinámicas de}

\section{la guerra,}

desafíos para

la paz.

\section{La experiencia de Colombia}

\section{Merly Guanumen}

merlyguanumen@gmail.com

Pontificia Universidad Javeriana

Bogotá - Colombia

Artículo recibido: 01/05/15

Artículo aprobado: 02/06/15

Para citar este artículo: Guanumen, M. (2015).

Dinámicas de la guerra, desafíos para la paz.

La experiencia de Colombia.

Ciudad Paz-Ando, 8(1), 40-61

DOI: http://dx.doi.org/10.14483/udistrital.jour. cpaz.2015.1.a03

\section{Uar dynamics, peace challenges. Colombia's experience}

\author{
Dinâmicas da guerra, \\ desafios para a paz. \\ A experiência da Colômbia
}

\section{Resumen}

Las guerras internas se caracterizan por la violencia y la atrocidad, la victimización masiva de civiles y el entorno de polarización política que crea en los países que las sufren, afectando en consecuencia vidas particulares, comunidades y la misma dinámica de las relaciones sociales. El fin de la guerra, y en consecuencia la construcción de paz, plantea desafíos a distintos niveles para estabilizar la sociedad, superar las prácticas de violencia instaladas y crear las condiciones para que las disputas que dieron origen al conflicto no se reactiven o se generen nuevas por incumplimientos de los acuerdos pactados o por otros retos emergentes.

Palabras clave: guerra interna, Colombia, paz, post-conflicto. 


\begin{abstract}
Internal wars are notorious for their violence and atrociousness. The massive victimization of civilians and an environment of political radicalization that gets hold of the afflicted country do in turn have an impact upon particular lives, communities and the overall dynamic of social relationships. The end of war, and therefore the buildup of peace, poses challenges upon many levels towards stabilizing societies, overcome entrenched practices of violence and provide sufficient conditions to prevent the reemergence of the disputes that set the conflict in motion in the first place, or the arousal of new ones stemming from the noncompliance of set agreements or new emerging problems.
\end{abstract}

Keywords: internal war, Colombia, peace, post-conflict.

\section{Resumo}

As guerras internas são caracterizadas pela violência, a atrocidade, a vitimização massiva de civis e o ambiente de polarização política nos países que as sofrem, afetando vidas particulares, comunidades e a dinâmica das relações sociais. O fim da guerra, e, assim, a construção da paz, propõe desafios de diferentes níveis para estabilizar a sociedade, superar as práticas da violência instaladas e criar condições para que as disputas, que foram a origem do conflito, não se reativem, ou produzam novas disputas por violação dos acordos feitos ou outros desafios emergentes.

Palavras-chave: guerra civil, Colômbia, paz, pós-conflito.

"Antes que me hubiera apasionado por mujer alguna, jugué mi corazón al azar y me lo ganó la violencia".

La Vorágine.

\section{Introducción}

广 Cuáles son los desafíos que enfrentan los países que finalizan guerras internas mediante acuerdos de paz? ¿Qué transformaciones deben afrontar esas sociedades para pasar de relaciones adversariales violentas a dinámicas democráticas? Estas preguntas guían las reflexiones del presente artículo, que mediante el análisis del caso de Colombia, se propone aportar a la comprensión de los procesos de transición desde sociedades en guerra a democracias estables por la vía de la paz pactada. El documento inicia con una caracterización de las guerras internas, luego se exponen las dinámicas de guerra y paz del caso colombiano, para finalmente analizar los desafíos de las sociedades en el post-conflicto. Este orden responde a una idea: "diseñar programas o proyectos de construcción de paz sin un completo análisis del conflicto es irresponsable y potencialmente peligroso". (Cheyanne Church \& Rogers, 2006, p. 12). 


\section{Guerra interna: violencia, victimización y polarización política}

Las guerras internas ${ }^{1}$ son confrontaciones armadas que pasan dentro de las fronteras de una unidad política soberana, reconocida por el sistema internacional, en el que las fuerzas militares del gobierno, o fuerzas armadas privadas a su servicio, o ambos, se enfrentan a una o más organizaciones armadas rebeldes para resolver una disputa inicial, conservar la soberanía en su territorio y restablecer el monopolio del uso de la fuerza.

Las operaciones armadas se desarrollan dentro de las fronteras estatales sin la participación o el apoyo directo de tropas de otros gobiernos a cualquiera de los bandos, los insurgentes controlan una parte del territorio, residen y reclutan en este, persiguen algún tipo de objetivo político, cuentan con una organización política y militar reconocible, y sus acciones tienen consecuencias devastadoras sobre los civiles, especialmente por la violencia que se ejerce directamente sobre ellos.

Una característica esencial de los conflictos armados internos es la disputa de soberanía y, por lo tanto, el carácter político del mismo, por lo menos en las razones iniciales de las hostilidades. Estas pueden iniciarse por disputas ideológicas entre las partes, bien de tipo político, por ejemplo frente a la manera como se debe gobernar o distribuir la riqueza y el bienestar de la sociedad; o por razones religiosas o morales, es decir, por el tipo de valores o códigos de conducta que deben regir a los ciudadanos; o bien por asuntos de identidad, es decir, de reconocimiento político y legal (moderado, compartir poder y ejercer derechos, o radical, división territorial y separación) de grupos étnicos, religiosos o políticos;

1 Se usarán los conceptos guerra interna y conflicto armado interno de manera sinónima. o también por control de recursos (bien por incentivos públicos o privados); por necesidades básicas insatisfechas (causas estructurales: reforma agraria, acceso a educación, salud, bienestar etc.); o por violaciones masivas de derechos humanos (represión política, persecución sistemática, genocidio) (Lekha, Martin-Ortega, \& Herman, 2010).

En cualquier caso, de lo que se trata es de desafiar el control político, militar, territorial y la legitimidad del gobierno en función al inicio de la guerra, bien para hacerse con este, dividirlo o transformar su régimen, por eso no basta con la sola existencia de tales condiciones para que se dé la guerra, es necesario el surgimiento de actores políticos que busquen transformar el estatus quo y que estén dispuestos a dirimir las disputas originarias por las armas y la violencia. Los meros incentivos privados de grupos armados ilegales, como explotación de recursos naturales (minerales, bosques, hídricos, tierra cultivable), actividades económicas ilegales (prostitución, narcotráfico, tráfico de personas, armas), control de activos productivos (fabricas, redes de abastecimiento, infraestructura), plantean desafíos de seguridad a los gobiernos, especialmente en el control territorial y la protección de los ciudadanos, pero no implican el desarrollo de una guerra interna si estos no tienen en su agenda el control o la disputa del poder político y además desarrollan acciones sostenidas en tal sentido.

Las fuerzas armadas legales, así como los insurgentes o las terceras fuerzas en confrontación, como paramilitares o mercenarios, deben ser distinguibles de la población civil porque cuentan con una estructura organizativa, un mando responsable (líderes) que ejerce algún tipo de control sobre una parte del territorio del Estado en el que combaten, sus miembros se diferencian generalmente por el 


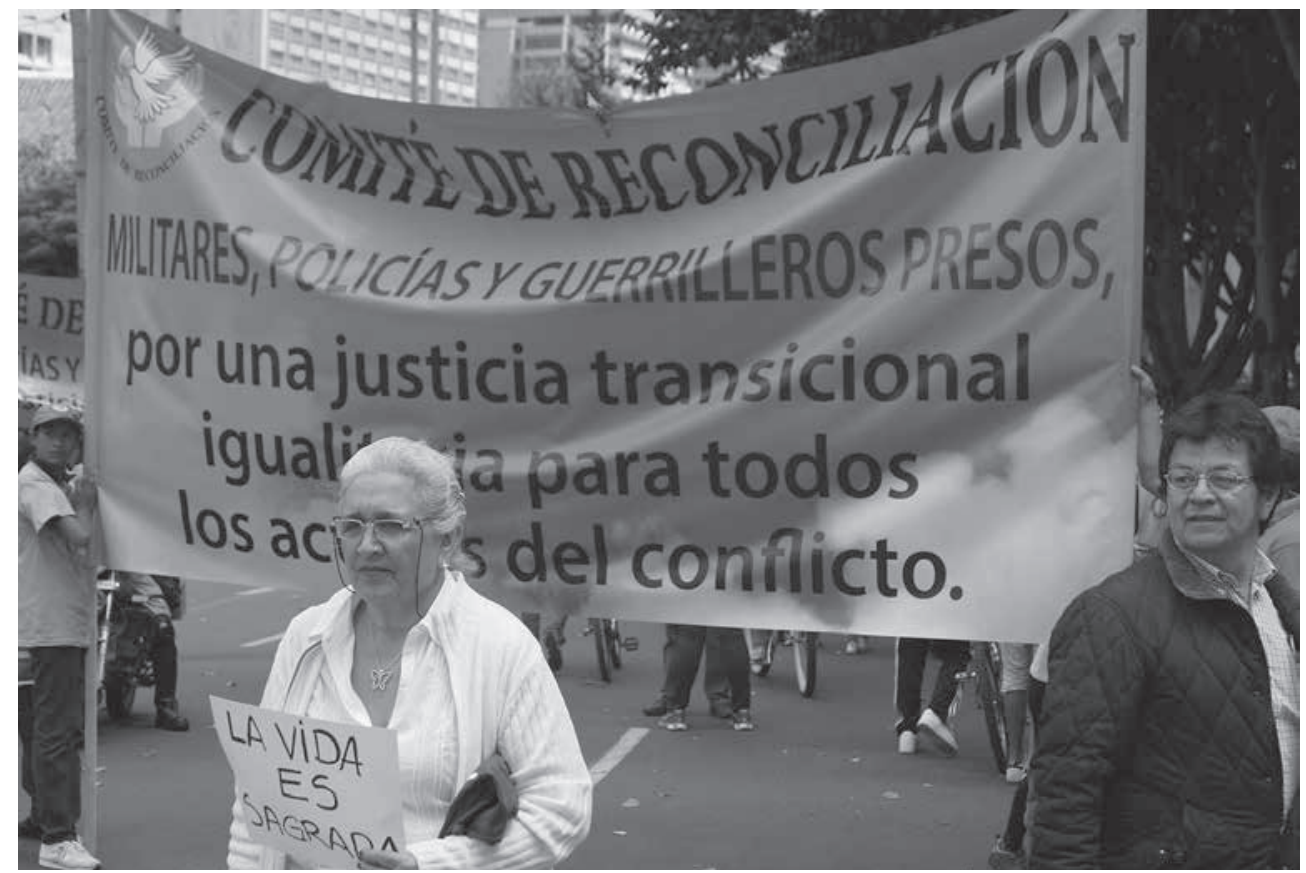

(c) IPAZUD

uso de uniformes militares, y portan armas de guerra visibles. En varios conflictos armados internos esas distinciones son menos claras, ya sea por la organización de los ejércitos, la preparación de los combatientes, e incluso la capacidad operativa para uniformar, total o parcialmente, a sus integrantes.

Las guerras internas no son sinónimo de guerra irregular, si bien muchas se desarrollan de esta manera, los combates regulares pueden ser la forma de la conflagración o fases superiores de la guerra de guerrillas hacia la derrota de un ejército nacional convencional. La guerra irregular, guerra de guerrillas o guerra partisana, es una contienda de base ideológica, se caracteriza por una relación militar que generalmente es asimétrica, aunque también puede ser simétrica, en la que un ejército rebelde combate una fuerza regular, y eventualmente otro bando irregular, asumiendo la ofensiva mediante el sigilo, tácticas de emboscadas, golpes sorpresivos y además el desarrollo de una estrategia política sostenida de apoyo popular a los insurgentes, "la guerri- lla tiene la iniciativa; es ella quien comienza la guerra y quien decide en dónde y cuándo hay que atacar" (Taber, 1970, p. 18).

La guerra de guerrillas es una manera de hacer la guerra y consiste en una lucha metódica, llevada a cabo paso a paso para alcanzar los objetivos intermedios que conducirán finalmente a los propósitos generales (toma del poder, cambio de régimen, división territorial, liberación nacional, etc.) (Galula, 1964). En desarrollo de esta, los insurgentes buscan debilitar la parte fuerte a través del acoso y el desgaste, por eso sirve a todo tipo de propósitos, guerras revolucionarias, de liberación, étnicas nacionalistas, colonialistas o imperiales, entre otras (Kalyvas, 2006).

El involucramiento de la población civil como medio de soporte del ejército insurgente o como estrategia contrainsurgente, define la guerra de guerrillas, bien sea en desarrollo de las operaciones militares (apoyo logístico, suministro de información) como en la estrategia política global (formación de partidos, apoyo de líderes sociales, comunitarios y políticos, 
control del poder local), especialmente en las guerras revolucionarias en las que se busca el cambio de régimen por la vía armada, "La batalla por la población es una característica importante de la guerra Revolucionaria» (Galula, 1964, p. 6). Aunque ese apoyo no responde sólo a la adhesión ideológica, los civiles también terminan atrapados en las dinámicas de control de los ejércitos, siendo obligados a la colaboración, el sometimiento o el asesinato y el destierro.

La otra cara del involucramiento de los civiles en las guerras irregulares son las estrategias contrainsurgentes, en las que los ejércitos regulares y el gobierno en cuestión buscan debilitar o destruir la capacidad ofensiva de las guerrillas mediante la arremetida directa, la persuasión o el ataque a sus probables bases sociales, restándoles de esta forma apoyos políticos y operativos en aras de restablecer la soberanía plena y "tratar de eliminar o atenuar las condiciones propicias para una insurgencia" (Galula, 1964, p. 6), por eso se imponen los métodos para convencer, controlar o someter a la población, sean estos legítimos o violentos.

El establecimiento de fuerzas paramilitares es asimismo una medida de contrainsurgencia que generalmente surge por debilidad operativa de las fuerzas estatales, incapacidad para controlar el territorio nacional en donde ocurre la guerra, o como respuesta local a la pérdida de poder, o la amenaza, a las elites políticas y económicas regionales (legales o ilegales) por parte de los rebeldes. Estos son grupos armados particulares que apoyan a las fuerzas regulares en la tarea de combatir a los insurgentes y controlar a la población a través de métodos violentos, sobre todo el asesinato, a los cuales en principio no puede recurrir el gobierno legítimo. Si bien estas bandas pueden surgir por iniciativa del propio gobierno o por acciones de particulares que intentan sustituir el rol del Estado en zonas de presencia o controladas por los insurgentes, como en los casos de Colombia, Perú o Guatemala, su característica principal es el vínculo, abierto o implícito, con el régimen interpelado.

Algunos surgen como apoyo a los insurgentes, operando "por fuera de su estructura militar "formal", incluyendo milicias populares y escuadrones de asesinos" (Arjona \& Kalyvas, 2005, p. 28) y otros para derivar además beneficios particulares o para administrar justicia privada en forma de venganzas. Aunque la violencia es el principal mecanismo de sometimiento de la población de las fuerzas paramilitares, en ocasiones la persuasión ideológica o el dominio de instancias políticas a nivel local son otras formas. El ejercicio del control político y territorial los configura como "autoridad local" de facto en ausencia o incapacidad del propio Estado para garantizar seguridad y orden, ganando con ello el apoyo de parte de la población.

Los paramilitares pueden tener diversos tamaños, desde escuadrones pequeños creados para controlar regiones o ciudades y dirigidos contra poblaciones específicas, sobre todo virtuales aliados de los rebeldes (líderes políticos, comunales, estudiantiles, intelectuales, periodistas) o marginados sociales considerados por estos como indeseables (prostitutas, homosexuales, drogadictos, ladrones, indigentes), hasta llegar a la dimensión de ejércitos organizados que dominan amplias zonas del territorio nacional mediante el apoyo de las elites políticas y económicas.

El lugar central de la población en las guerras de guerrillas supone un desafío práctico y teórico para establecer la distinción entre combatientes y civiles, tanto porque son sujetos de la violencia que los ejércitos ejercen para debilitar a sus adversarios, por su condi- 
ción de objetivo para la conquista ideológica, como porque son fuentes de apoyo logístico y operativo de los bandos. Por ello, la violencia y la atrocidad hacia los civiles son recurrentes en los conflictos armados internos. La guerra es en esencia un espacio relacional de violencia que produce un contexto amplio e inmediato para su propio sostenimiento, y genera unas formas de socialización que interiorizan la agresión en los comportamientos y en la psiquis colectiva (Martin-Baró, 2003), bien como estrategias para lidiar con los desafíos de la convivencia o la precariedad material y social que la conflagración produce, o como mecanismo oportunista para sacar ventaja de la debilidad del más indefenso.

La atrocidad es un rasgo presente en las guerras internas y se refiere al proceso de deshumanización de las víctimas en la psiquis del verdugo que lleva a que estos sean "“cosificados" antes de ser aniquilados" (Semelin, 2002, p. 4). Esta es la expresión de un universo normativo fragmentado por la guerra en la cual los códigos de conducta del tiempo de paz que se supone estructuran la sociedad en su conjunto, se rompen para dar paso a moralidades particulares determinadas por las coordenadas amigo-enemigo (Schmitt, 1998), a través de las cuales se es leal con los propios para protegerlos y aportar a la supervivencia colectiva (nosotros-seguros), y como efecto reflejo se atenta contra el otro-amenazante, ya que su sola existencia supone un cuestionamiento a la propia identidad grupal y a la causa que la motiva. La moral escindida es un reflejo de la polarización que la guerra supone en el universo político y social.

Esta también es explicada por el colapso de los mecanismos sociales de control de la violencia que genera la guerra, con lo cual, a decir de Kalyvas (2006), se crea una cultura del embrutecimiento generalizado, en entor- nos en que las instituciones de protección ciudadana tienden a fallar o ralentizarse, haciendo que se promueva la venganza como forma de compensación, la violencia preventiva para resolver los dilemas de seguridad, y la proliferación de "grupos armados indisciplinados" como estrategia oportunista.

La exposición constante a la violencia, la eliminación o debilitamiento de los controles sociales, la reducción de los costos de producirla, la mayor visibilidad y relevancia de quienes son propensos a esta y el incentivo de "las habilidades violentas" (Kalyvas, 2006, p. 87), son dinámicas que también incrementan la barbarie en las guerras internas y en las que terminan atrapados los civiles, como víctimas y victimarios a la vez. La violencia se rutiniza y la gente se acostumbra a las imágenes y narraciones de atrocidades, desplazando la frontera de lo permitido y lo que no lo es, la vida cotidiana se inunda de instancias de criminalidad para tramitar el conflicto diario y las diferencias, dando paso a los oportunistas y mejor dotados para la agresión, sobre todo los hombres jóvenes. Se establece entonces una forma de vivir que se adapta a la violencia, y que normaliza lo anormal.

La barbarie es un flujo entre el campo de batalla y la vida cotidiana. La exposición constante de los combatientes a la violencia también prepara su psiquis para la barbarie contra los civiles y a la vez este fenómeno puede incrementar la barbarie en el combate, con lo cual se genera un círculo vicioso que disuelve las fronteras de las distintas violencias. El reconocimiento de la dinámica circular de la violencia en las guerras internas, es decir del campo de batalla hacia los ámbitos civiles, permite establecer coordenadas para entender la manera como esta ocurre según el actor que la provoca, ya sea un combatiente o un civil. 
Como afirmara Hanna Arendt, la violencia es "un fenómeno por derecho propio" (2006, p. 48) que en la guerra se produce de distintas maneras; de forma horizontal, es decir, de combatiente a combatiente y entre civiles; o vertical, es decir, de combatientes a civiles y viceversa, y a menos que sea el acto individual de una mente perturbada, casi siempre sirve a propósitos estratégicos, "nadie, o por lo menos pocos derraman la sangre humana por solo derramarla" (Séneca, 2015, p. 83). La guerra es, de hecho, la violencia legítima entre combatientes cuando se da en el campo de batalla y cumpliendo los criterios de justicia (in bello y ad bellum), pero esta puede desbordarse y derivar en otras dinámicas de barbarie que ocurren más allá de lo que se considera legítimo para los ejércitos, dando paso a los crímenes de guerra.

La victimización ${ }^{2}$ como producto inmediato de la guerra va de lo colectivo a lo individual y viceversa; es decir, el trauma es producido por el contexto de violencia de la confrontación política, afectando vidas particulares y comunidades al mismo tiempo, lo que hace necesario implementar acciones en ambos niveles para superar tal estado, es decir, en la salud mental y en el tejido social. Las consecuencias de la guerra van "construyendo subjetividades, realidades, lenguajes y prácticas sociales, que a la postre adquieren "dinámica" propia y pasan a formar parte de las características del ámbito social y comunitario" (Martínez \& Arévalo, 2009, p. 16).

La recurrencia y la escala de la violencia que se produce en la guerra termina afectando la vida cotidiana no sólo de quienes viven en las zonas de combate si no de la sociedad

2 Definida como la acción de victimizar, de convertir a alguien en víctima. Algunos enfoques de la sicología usan este término más en un sentido disfuncional, como una forma de prolongación patológica de la condición de víctima. en su conjunto, dado que la omnipresencia de la violencia conduce al estímulo de comportamientos agresivos en las relaciones sociales y en las prácticas públicas, estas últimas determinadas por la polarización política que la confrontación armada provoca. La doble condición individual y colectiva de la victimización ubica el análisis de este fenómeno y sus consecuencias en la confluencia dialéctica de la psicología del individuo y los procesos políticos, "desde el sujeto y desde la sociedad, a través de las relaciones sociales que lo expresan" (Kornfeld, 1991, p. 9), ya que el trauma individual condiciona las relaciones sociales en las que el sujeto está inmerso.

Por eso es conveniente una perspectiva de análisis psicosocial que permita entender la manera como la victimización en contextos de guerra afecta las dinámicas micro (individuales, familiares, comunitarias) y macro sociales (políticas, sociales, culturales). En esta línea nos apoyaremos para analizar los desafíos del post-conflicto.

\section{Colombia, dinámicas de guerra y violencia}

Colombia vive un conflicto armado interno desde los años sesenta, en el cual se han involucrado las fuerzas gubernamentales, diferentes guerrillas izquierdistas, ejércitos paramilitares de extrema derecha, y mafias de narcotraficantes que han contribuido a la economía de la guerra. Es una guerra irregular, de base ideológica, con ejércitos organizados, disputa de soberanía al Estado e implicaciones regionales, sobre todo por la afectación a los países de frontera, y en el que las principales víctimas han sido los civiles, llegando a considerarse como "guerra degradada" por la atrocidad desplegada por todos los combatientes (Sánchez, 2013). 
La violencia ha dejado alrededor de cinco millones de víctimas, sobre todo civiles, resultado de masacres, asesinatos selectivos, desapariciones, secuestros, torturas, mutilaciones, reclutamiento ilícito, violencia sexual, o desplazamiento forzado (Centro Nacional de Memoria Histórica, 2013). En Colombia, la muerte de civiles por efecto de la guerra ha ocurrido de manera cotidiana, selectiva, silenciosa, en partes muy aisladas de los centros urbanos y acompañadas de crueldad y terror (Centro Nacional de Memoria Histórica, 2013) y las consecuencias de décadas de violencia sistemática hacia la población civil se reflejan no sólo en el balance de víctimas y de daños materiales, sino también "en el tejido de mecanismos de exclusión, de impunidad, de despojo y de terror que ha ido configurando el diario acontecer de nuestra nación" (Centro Nacional de Memoria Histórica, 2013, p. 13).

Los ejércitos han sido las Fuerzas Armadas Revolucionarias de Colombia (FARC), la principal guerrilla del país, de origen campesino, orientación política comunista y desde finales de los años noventa, inmersa en el negocio del narcotráfico. En segundo lugar está el Ejército de Liberación Nacional (ELN), de tipo "marxista-católico", surgida bajo la inspiración de la Revolución Cubana y las teorías del Che Guevara, y aunque sigue operando en la zona petrolera del noroccidente del país, se encuentra debilitada. De igual manera, hay otras guerrillas izquierdistas de menor tamaño, que mediante acuerdos de paz se desmovilizaron en los años noventa, algunas surgidas de sectores urbanos medios de las grandes ciudades como el Movimiento 19 de Abril "M-19" (1970-1991), el Ejército Popular de Liberación (1968-1991), o la Corriente de Renovación Socialista (1989-1994), y una guerrilla de tipo indigenista llamada Movimiento Armado Quintín Lame (1984-1991).
Por otra parte, las fuerzas paramilitares de extrema derecha -cuyos orígenes más próximos se asocian a la economía agro-industrial y minera, legal e ilegal, como la producción bananera, ganadera, esmeraldera y sobre todo asociadas al narcotráfico- surgieron como mecanismos de los narcotraficantes para expandir su poder, controlar tierras, y someter autoridades y campesinos, pero también como respuestas locales a la actividad de las guerrillas que mediante extorsiones, asesinatos selectivos, secuestros, presionaban a esos sectores y a sus bases sociales $^{3}$.

La mayoría de estos grupos confluyeron en una organización denominada Autodefensas Unidas de Colombia (AUC), que desde los años noventa y hasta 2002 operó sobre todo en el norte y el centro del territorio nacional, pero con acciones en distintas zonas del país, sobre todo dirigidas a la población civil, convirtiéndola en una de las mayores responsables de la degradación de la guerra por las atrocidades cometidas ${ }^{4}$. Entre 2003 y 2009, el gobierno adelantó un proceso de negociación y sometimiento que derivó en la desarticulación de esta organización, así como el procesamiento judicial y la extradición de sus principales líderes a los Estados Unidos, acusados por delitos de narcotráfico.

La desmovilización de la organización paramilitar y la captura o eliminación de los grandes narcotraficantes abrió una nueva

3 Una investigación reciente de la Fundación Ideas Para la Paz de Colombia, concluye que hay una relación histórica y geográfica de convergencia entre las organizaciones paramilitares y el narcotráfico. Me acojo a estas conclusiones y a la idea de que el discurso contrainsurgente fue más una fachada que una realidad del paramilitarismo (Echandía, 2013)

4 Entre 1996 y 2002 se cometieron el 55\% del total de las masacres, de las cuales 59\% se atribuyen a los paramilitares como medio de castigar la movilización social, el éxito político de la izquierda y "limpiar" las zonas de influencia guerrillera. Los paramilitares son responsables de asesinatos atroces, desplazamiento forzado, violencia sexual contra las mujeres, secuestros, desapariciones, torturas, mutilaciones (Centro Nacional de Memoria Histórica, 2013). 
fase del crimen asociado a esta y otras actividades ilícitas como la minería ilegal, el secuestro y la extorsión a comerciantes, ya que el vacío de poder local fue rápidamente copado, o se encuentra en disputa, por organizaciones de menor capacidad conocidas como "BACRIM" (bandas criminales), integradas por excombatientes paramilitares y delincuentes comunes. Estas bandas criminales disponen de la experiencia de los excombatientes, de sus prácticas de violencia atroz hacia los civiles, y del mercado negro de armas que la guerra ha dejado en Colombia, convirtiéndolas en un riesgo de seguridad que rebasa la capacidad operativa de la policía nacional y en uno de los principales desafíos en la pacificación del país.

El combustible de la guerra ha sido el narcotráfico, este negocio ha inyectado abundantes recursos a los ejércitos, permitiendo su fortalecimiento operativo y su expansión, bien por participación directa en alguna parte de la cadena de producción y distribución, o por el establecimiento de "impuestos" a la actividad en las zonas de presencia de los ejércitos, como el "gramaje", un "impuesto guerrillero" a los cultivadores de coca. Las FARC se han involucrado tanto en el negocio que hoy el gobierno de los Estados Unidos los considera una organización narcotraficante y terrorista, al igual que los paramilitares.

El vínculo entre guerra insurgente y narcotráfico, en un momento en el que se percibía a Colombia como un estado fallido, y el encuadramiento del problema en las coordenadas de preocupación de Washington por parte del gobierno colombiano de Andrés Pastrana (1998-2002), posibilitaron la participación indirecta de Estados Unidos en el conflicto a través del Plan Colombia, un paquete de cooperación económica para el fortalecimiento de las fuerzas militares y las instituciones judicia- esta vía cambió la relación de fuerzas entre Estado e insurgentes, y con el debilitamiento de las FARC se abrieron las posibilidades al actual acercamiento político.

La violencia intensa que ha vivido el país por más de cinco décadas ha dejado profundas marcas en las dinámicas políticas y sociales de los colombianos, y aunque hoy la acción de los ejércitos ha disminuido considerablemente, aumenta la criminalidad en las grandes ciudades, así como la violencia doméstica. Colombia se mantiene como uno de los países de la subregión con tasas altas de homicidio, 30,8 por cada 100,000 habitantes (UNODC, 2013); cifras asociadas sobre todo al crimen organizado y la delincuencia común. La violencia sigue siendo un recurso constante de los actores y la sociedad para alcanzar sus objetivos.

\section{Narrativas de paz y guerra}

Colombia ha oscilado entre narrativas y políticas de seguridad adversas a escenarios de paz, impulsados por las comunidades afectadas, organizaciones políticas, sociales, intelectuales o el mismo gobierno. El tratamiento del conflicto no ha obedecido a una política de Estado de largo plazo, sino a las dinámicas y relaciones de poder, y propósitos de cada gobierno. Por eso también los discursos oficiales han respondido a la geopolítica global; así, en tiempos de la Guerra Fría, los enemigos eran las "guerrillas comunistas"; en medio de la guerra contra las drogas, las "guerrillas narcoterroristas"; y tras el 11 de septiembre, los "terroristas".

En medio de estos marcos de representación más dirigidos a continuar por el camino de la fuerza, los ciudadanos también han contribuido a impulsar mecanismos de acercamiento para establecer acuerdos de paz. La moviliza- 
ción por la paz y por los derechos humanos también ha sido la respuesta a la violencia, así entre 1978 y 2003, particularmente en la segunda mitad de los años noventa, esta fue "una movilización social de un nivel significativo, con repertorio creciente de acciones y con cobertura nacional" (García-Durán, 2006, p. 12).

Entre los intentos de resolver la guerra por la vía de la negociación política, se observan tres momentos: los acuerdos parciales con las FARC en 1984; la desmovilización y reinserción de varias guerrillas en la década del noventa, y el sometimiento de las AUC entre 2003-2009; y las negociaciones para alcanzar acuerdos de paz con las FARC en 19982002, y las actuales entre 2012 y 2014 . Se consideran estos por el nivel de desarrollo alcanzado, si bien también se dieron acercamientos en los gobiernos de César Gaviria (1990) y Ernesto Samper (1994), además de los intentos con el Ejército de Liberación Nacional (ELN), que aunque mencionamos no abordaremos por razones de espacio.

\section{Acuerdo Parcial con las FARC}

Se trata de los acuerdos pactados entre las FARC y el gobierno nacional en La Uribe (Meta), los cuales fueron posibles gracias al cambio de narrativa oficial. Así, de un gobierno previo de mano dura (1978-1982) hacia las guerrillas y a la oposición de izquierda, se pasó a un Presidente (1982-1986) que prometió negociaciones y mayor apertura democrática. Se acordó el cese al fuego (19821986), más espacio político a los insurgentes para su incorporación progresiva en la sociedad y abandono del secuestro, la extorsión y el terrorismo por parte de los insurgentes. Así nació la Unión Patriótica (UP), partido que logró elegir 16 alcaldes, 256 concejales y 16 representantes al Congreso de la República.
El paramilitarismo asoció cese al fuego con incremento de secuestros y extorsiones de las FARC, configurando a la UP como un objetivo militar, lo cual llevó a que en los siguientes 20 años asesinaran a tres mil militantes, entre ellos dos candidatos presidenciales y 13 parlamentarios. La violencia ejercida contra esta organización radicalizó la posición de las FARC, negándose a cualquier tipo de acuerdo, hasta 1998 nuevamente.

\section{Desmovilización de guerrillas y paramilitares}

En los años noventa se firmaron acuerdos de paz con diferentes guerrillas que incorporaron a la vida social y política cerca de 5.000 combatientes. El proceso más importante durante este periodo se realizó con el movimiento guerrillero $\mathrm{M}-19$, que derivó en un cambio constitucional democratizador en 1991 para incorporar los acuerdos, lo cual facilitó negociaciones y desmovilización de otros siete grupos. Esta generación de acuerdos de paz, sin mecanismos de justicia transicional, permitió la transformación de combatientes en actores políticos legítimos, mediante procesos de desarme, desmovilización y reinserción, emergiendo con ello nuevos partidos políticos.

Las negociaciones de paz con el M-19 se dieron tras una década de violencia asociada no sólo a las guerrillas, sino también a la irrupción de los carteles del narcotráfico que atacaron de forma directa las instituciones públicas, minando la legitimidad y capacidad del Estado. Tres de los candidatos presidenciales de la campaña 1988-1992 fueron asesinados por las mafias y el terror como forma de presión política que se vivió en ciudades como Bogotá, Medellín y Cali, dejando miles de muertes civiles. La guerra por primera vez se sentía con fuerza en las ciudades y la sociedad se sintió atemorizada y en riesgo. 
El M-19 en 1986 se tomó el Palacio de Justicia en Bogotá, siendo igual de brutal la respuesta de las Fuerzas Militares, lo que cobraría la vida de 98 personas, entre ellas 11 magistrados de las altas cortes. Este episodio que deslegitimó como actor político al M-19, contribuyó a minar su moral como ejército, abriendo paso a las alternativas de paz dentro de la organización. Esta y las demás guerrillas desmovilizadas se transformaron en partidos políticos que en el largo plazo terminaron diluyéndose en las coaliciones de izquierda que hoy están presentes en el debate democrático, sin que ninguna haya optado por el camino de la guerra. Este proceso se ha considerado como exitoso, dado que mostró cómo se podía terminar la guerra por el camino de la negociación política, logrando transformaciones.

La constitución de 1991, expresión de los acuerdos, contribuyó a ampliar la democracia, al menos a un nivel formal, aunque también evidenció las debilidades en los procesos de reinserción económica y social de los ex-combatientes y los riesgos de seguridad. Además del máximo líder del M-19, entre 1998 y 2005, 160 militantes de esa organización fueron asesinados, lo que corresponde al 20\% de todos los homicidios cometidos contra exguerrilleros de los distintos procesos de paz de los años noventa. Los mecanismos de justicia transicional ${ }^{5}$ también se han criticado, sobre todo por las amplias concesiones a los excombatientes, el desconocimiento de las víctimas, y el incumplimiento de amnistías e indultos para algunos casos (Patiño, Grabe, \& García-Durán, 2009). El último y más reciente acuerdo se dio con las Autodefensas Unidas de Colombia (AUC), derivando en la desmovilización de 31.761 combatientes entre 2002 y 2006, si bien muchos

5 Se trata de mecanismos diseñados para lidiar con violaciones masivas de derechos humanos, que buscan garantizar la verdad de los hechos y un mínimo de justicia (ICTJ, 2011). de estos actualmente operan en las "Bacrim" (Echandía, 2013), (Nussio, 2013). El antecedente de desarme fue el sometimiento a la justicia de las autodefensas durante el período del Presidente Gaviria (1990-1994), como parte de la persecución a los narcotraficantes, pero estas estructuras persistieron y se volvieron más poderosas en el período siguiente.

El cambio más importante se da luego de la muerte de Pablo Escobar en 1993, cuando estos grupos implementaron una estrategia "encaminada a darle a las estructuras armadas al servicio del narcotráfico una base de legitimidad, ligándolas a la lucha contrainsurgente, ya que ante la ley no eran más que una simple expresión criminal” (Echandía, 2013, p. 28). La estrategia deriva en 1997 en la creación de las AUC, un recurso organizativo para legitimarse y facilitar negociaciones con el Estado, que además significó el dominio de los paramilitares sobre los narcos en su simbiosis. Este es el período de mayor expansión territorial y también del uso sistemático de terror contra supuestos simpatizantes de la guerrilla, el 90\% de sus víctimas fueron civiles.

Un importante cambio de narrativa y de desarrollo del conflicto se da hacia el año 2002, cuando es elegido Álvaro Uribe (20022010), quien logró el debilitamiento político y militar de las FARC, gracias también al Plan Colombia. Su discurso permitió configurar a las FARC como la principal amenaza a la seguridad de los colombianos, denominándolos "narcoterroristas", a los paramilitares como delincuentes políticos por su accionar contrainsurgente, y a la guerra se le negó tal carácter, definiéndola como una "amenaza terrorista", aprovechando la retórica de la guerra global contra el terrorismo. La política de Seguridad Democrática, nombre de su estrategia, significó un rompimiento con las políticas de paz de sus predecesores. 
El proceso de paz con los paramilitares, controversial en la sociedad colombiana y en la institucionalidad internacional de derechos humanos, que algunos califican como parcial porque solo logró el desmonte de la estructura militar más no la organización mafiosa, (Gallón, 2014) deja lecciones para los futuros acuerdos con las FARC, y para otras negociaciones de paz con grupos armados de este tipo. En primer lugar, el reconocimiento de los combatientes de las AUC que fue problemático por cuanto se desmovilizaron 36.000, cuando las cifras del Ministerio de Defensa en 2012 eran de 12.000 paramilitares, lo cual hace suponer que narcotraficantes "puros" compraron "franquicias" para hacer parte del proceso, legalizar sus organizaciones y aprovecharse de los mecanismos de justicia transicional.

El mayor déficit de los acuerdos han sido las víctimas y sus derechos, bien por el marco normativo aprobado, los riesgos de seguridad que implican las nuevas estructuras "neoparamilitares", como por la extradición de 30 de los principales líderes a los Estados Unidos por delitos de narcotráfico, dificultando los procesos judiciales en Colombia por crímenes de guerra y de lesa humanidad. Se negociaron penas máximas de ocho años de cárcel para los victimarios, muchos no han tenido ningún proceso judicial, la recuperación de tierras para quienes fueron desplazados es una tarea peligrosa y ya le ha costado la vida a varios líderes campesinos, "hay poca tierra devuelta y muchos muertos; mucho trámite y pocas restituciones", dice uno de ellos (El Tiempo, 2014).

Si bien el proceso logró la reducción de los combatientes, desarticuló la estructura militar de las AUC, permitió conocer su funcionamiento y sus cómplices, ha facilitado en algunas zonas la devolución de tierras a los campesinos, el rearme de combatientes en las "bandas criminales" y la violencia que es- tos producen son una nueva fase del problema. El desafío institucional para el proceso de desarme, desmovilización y reincorporación ha sido garantizar las condiciones para que los combatientes no reincidan en la violencia, sumándose a las estructuras armadas que aún persisten en el país o estableciendo nuevas.

Aunque el Estado ha construido un esquema gubernamental a partir de los procesos de paz anteriores y en diálogo con los Estándares Integrados de Desarme, Desmovilización y Reintegración de Naciones Unidas, dirigido a ofrecer esas condiciones en términos de apoyo socioeconómico, atención psicológica para el combatiente y las comunidades de origen, programas de educación e inserción laboral, prevención de reclutamiento, entre otros ( $\mathrm{He}$ rrera \& González, 2013), lo cierto es que, según algunas investigaciones académicas, en Colombia se evidencia un proceso de rearme paramilitar a través de las bandas criminales, debido, sobre todo, a que el Estado no ha construido la institucionalidad suficiente y la legitimidad necesaria para controlar esas zonas.

\section{Negociaciones para alcanzar acuerdos de paz con las FARC}

El Caguán es el nombre popular de los diálogos adelantados entre las FARC y el Gobierno en el período 1998-2002, se les conoce así por el área en donde se desarrollaron. El acercamiento obedeció a un encuentro entre el candidato presidencial Andrés Pastrana y el máximo líder de las FARC, Manuel Marulanda Vélez, además actuó como respuesta a una de las mayores movilizaciones ciudadanas en contra del conflicto armado: "Mandato Ciudadano por la Paz y la Libertad" de 1997.

6 Iniciativa ciudadana que en este año logró el voto de cerca de diez millones de colombianos para rechazar la violencia y apoyar iniciativas de paz. 
Las principales características de este proceso fueron: la negociación avanzó en medio de la confrontación militar en el resto del país; contó con la observación y facilitación de gobiernos europeos y de Latinoamérica; la participación de la sociedad civil fue masiva, más de 25.000 delegados, a través de audiencias públicas transmitidas por televisión; se construyó un documento denominado "Agenda común por el cambio hacia una nueva Colombia" que incluyó temas como derechos humanos, política agraria, recursos naturales, modelo de desarrollo económico y social, reforma a la justicia y al Estado, relaciones internacionales, entre otros (INDEPAZ, 2014).

A pesar del involucramiento de la sociedad civil, el adelantar las negociaciones en medio de los combates dificultó la construcción de un entorno de confianza entre las partes, lo cual imposibilitó el consenso y minó la voluntad de las mismas para llegar a acuerdos en los temas fundamentales. Las acusaciones mutuas sobre incumplimientos y "juego sucio" desalentaron las posibilidades de éxito en este proceso; el gobierno señaló a las FARC de usar la zona para operaciones de secuestro, extorsión y narcotráfico, y estas a su vez acusaron al Estado por permitir el incremento del paramilitarismo y no tener voluntad real de negociación.

La ruptura de los diálogos se sucedió por el secuestro de un avión comercial y su aterrizaje forzoso en la zona del Caguán, con el objetivo de secuestrar a un senador de la República que iba como pasajero, además de muchos más incidentes a lo largo del período. El pesimismo sobre la voluntad real de las FARC para lograr la paz por acuerdos políticos y la sensación de frustración generalizada crearon las condiciones políticas y emocionales para el cambio de discurso hacia opciones de fuerza y derrota militar, siendo así posible la elección del presidente Álvaro Uribe, bajo su lema
"Mano firme, corazón grande": "Mano firme" para los que persisten en la guerra y "corazón grande" para los que se quieran desmovilizar?.

El acercamiento en curso, que resultó sorprendente cuando se esperaba continuidad en la política de guerra frontal, se ha desarrollado procurando no repetir los errores del pasado. Aunque se adelanta en medio de las hostilidades porque no se acordó cese al fuego, a pesar de la declaratoria unilateral posterior de las FARC, se lleva a cabo en La Habana lejos de las interferencias mediáticas y los saboteadores que caracterizaron el acercamiento anterior; con poca participación de la sociedad civil, y en un régimen de secretismo sólo interrumpido por ruedas de prensa para rendir cuentas de los avances, o cuando la dinámica de la guerra lo obliga o interfiere con el proceso.

El acuerdo de 2012, con la garantía de Noruega y Cuba, y el acompañamiento técnico y logístico de Venezuela y Chile, se basa en "la disposición total del Gobierno Nacional y de las FARC-EP de llegar a un acuerdo" y busca alcanzar consensos en: 1) Política de desarrollo agrario integral; 2) Participación política; 3) Fin del conflicto; 4) Solución al problema de las drogas ilícitas; 6) Victimas; 7) Implementación, verificación y refrendación (Mesa de Conversaciones , 2012).

Aunque los colombianos apoyan la salida negociada al conflicto armado, no están de acuerdo con la participación en política de las FARC, o los mecanismos de justicia transicional que limiten o suspendan las penas. La

\footnotetext{
7 La desmovilización y la reincorporación individual de combatientes fue una estrategia de desarme implementada de manera sistemática durante el gobierno de Álvaro Uribe Vélez, que a través de medios de comunicación, sobre todo radio, buscó persuadir a los combatientes, principalmente de las guerrillas, a abandonar esas organizaciones y entregarse a las autoridades públicas. Se calcula que entre 2003 y 2012, 22.990 combatientes se desmovilizaron de esta forma, del total de 54.839 desmovilizados en el período. La distribución de desmovilizados es la siguiente: AUC, 35.314, FARC, 15.852, ELN, 3.195, otros 478. De estos 10.212 abandonaron la reintegración, 8.030 no entraron efectivamente al proceso de reintegración, y 2308 han muerto (El Tiempo, 2012).
} 
mayoría apoya una salida negociada con la guerrilla, $71,6 \%$ en zonas de conflicto y $58.1 \%$ a nivel nacional, pero es escéptica frente a la desmovilización definitiva de las FARC, a lograr acuerdos en el corto plazo y a la reconciliación entre ciudadanos y combatientes. Mucho más lo es frente a que las FARC formen un partido político (65\% en zonas de conflicto está en desacuerdo y $71 \%$ a nivel nacional), a que el gobierno les entregue espacios de representación o que participen en próximas elecciones (USAID, Americas Barometer, VanderBilt University, Universidad de los Andes, Observatorio de la Democracia, 2013).

Los colombianos han acumulado experiencias, algunas alentadoras y otras muy frustrantes frente a los acuerdos de paz; por eso las cifras son contradictorias. Si bien muestra apoyo al proceso, también reflejan un rechazo generalizado a las FARC como contradictor político, lo cual establece un reto mayor para el post-conflicto. El uso del secuestro como forma sistemática de financiación y de presión política, la degradación de los métodos y recursos de guerra, los vínculos estrechos con el narcotráfico, y las frustraciones del proceso de paz del Caguán, así como ocho años de discursos oficiales sobre la "amenaza terrorista" de las FARC, son algunas de las razones.

El Presidente Santos ha intentado re-politizar el debate con esa organización, volviendo a denominar la guerra como un "conflicto armado interno" pero sin una narrativa general lo suficientemente fuerte que convenza a los ciudadanos sobre la necesidad de la reconciliación, menos aun cuando la violencia continúa, las FARC siguen vinculadas al narcotráfico, se niegan a reconocer o rendir cuentas sobre sus crímenes y el Presidente anterior es el mayor saboteador del proceso.

\section{Desafíos de la paz}

La finalización de las guerras internas mediante acuerdos de paz implican grandes retos para los países que las enfrentan, sobre todo para desactivar la violencia incrustada en las dinámicas sociales y políticas, superar la victimización masiva, recuperando vidas individuales y comunidades afectadas, así como transformar la polarización política propia de la guerra, logrando el respeto del contendor político.

Los gobiernos se enfrentan al desafío de implementar diseños institucionales y políticas públicas que garanticen el cumplimiento de los acuerdos pactados, la atención integral a víctimas y desmovilizados, la construcción de escenarios de reconciliación entre la ciudadanía y los combatientes, la ejecución de mecanismos de justicia transicional y la reconstrucción de las zonas devastadas por la guerra y la violencia.

La transición a la democracia, luego de conflictos de larga duración y degradados, es un proceso complejo de cambio político, social y cultural que transforma al enemigo de la guerra en ciudadano o contradictor político durante la paz, sobre la base de mecanismos de reconciliación a todos los niveles, sistémico, grupal e individual (Ugarriza, 2013), y en diferentes momentos, el corto, mediano y largo plazo.

\section{El corto plazo: víctimas y combatientes}

Las primeras etapas tras los acuerdos de paz están centradas, en la mayoría de los casos, en el cese al fuego y los procesos de desarme, desmovilización y reintegración (DDR) de combatientes, la atención a las víctimas y las medidas de justicia transicional (Uppsala University. Department of Peace and Conflict Research, 2014), ya que es necesario atender 
a la población más directamente afectada por la guerra. EL DDR implica políticas de atención integral a los combatientes en sintonía con las necesidades y retos del contexto, las formulas estandarizadas no siempre funcionan (Nussio, 2013) para facilitar el tránsito a la condición de ciudadanos activos y, en algunos casos, a actores políticos participantes en debates electorales. Estas medidas buscan asegurar condiciones de bienestar social, psicológico, económico y político, grupal e individual, que reduzcan las posibilidades del rearme en las etapas tempranas del postconflicto, pero también que desincentiven ese recurso en el largo plazo.

En contextos donde los acuerdos de paz son parciales porque otros ejércitos siguen activos, emergen facciones disidentes de los que se desmovilizan, o porque las condiciones socio-económicas son precarias ${ }^{8}$, el reto para la sociedad es disminuir los incentivos para que los excombatientes vuelvan a las armas. En el caso de Colombia, como lo muestran las experiencias de DDR de los noventa, y en particular la de los paramilitares, la mayor dificultad se centra en los estímulos sociales, económicos y psicológicos (dificultad en la adaptación a la nueva vida) que implica el negocio del narcotráfico, muy fuerte aún en el país, y otro tipo de actividades criminales como la minería ilegal, el contrabando, el secuestro, la extorsión, entre otros. También es necesario trabajar en estrategias integrales de prevención del reclutamiento forzado, especialmente de niñas, niños y adolescentes para limitar las posibilidades de nuevos ejércitos o grupos criminales.

8 Los anteriores procesos de paz en Colombia han mostrado que "El desempleo se ha considerado como una de las principales causales de retorno a la ilegalidad y reincidencia en actividades criminales, por lo cual, y como se ha reflejado en los procesos de DDR aún en curso, la formulación de programas de reintegración económica es una prioridad sine qua non" (Herrera \& González, 2013, pág. 281).
El caso de Colombia nos deja ver que sin un adecuado proceso de DDR, el recurso a la violencia es un camino disponible en el postconflicto, sobre todo cuando se cuenta con espacios de criminalidad permanente por debilidad del Estado. La reincorporación de los excombatientes a la sociedad es un proceso de doble cara (individual y colectivo) que demanda un enfoque integral de reintegración comunitaria, involucrando en los planes de atención a las familias y las comunidades de acogida (Herrera \& González, 2013), además de construir y difundir narrativas de reconciliación política que posibiliten la aceptación por todos los ciudadanos de los cambios pactados para finalizar el conflicto.

La experiencia con la desmovilización de los paramilitares, e incluso con las negociaciones en curso con las FARC en Colombia, muestra que sin un adecuado manejo de la dimensión emocional y discursiva de la reconciliación, además de efectivos procesos de justicia transicional, los ciudadanos se resisten a aceptar a los combatientes como actores políticos, sobre todo en contextos donde estos han sido responsables de crímenes de guerra. La transformación del combatiente en ciudadano o contradictor político y su aceptación por la mayoría de la sociedad depende especialmente del desarrollo de mecanismos de justicia transicional que aseguren espacios de rendición de cuentas, reparación a las víctimas y de reconocimiento de la verdad frente a la sociedad.

La verdad es necesaria para la reconciliación; la negación o banalización de la violencia, del sufrimiento de las personas, de la desestructuración de comunidades y modos de vida, alientan comportamientos de venganza y aleja las posibilidades de reconstrucción de confianza y del tejido social necesarios para construir paz. En varias transiciones 
de guerras internas hacia post-conflictos se han establecido tribunales o comisiones de la verdad para hacer balance de los crímenes cometidos y establecer los responsables, aunque no siempre se correspondan con justicia efectiva para las víctimas.

Los procesos de paz de los años noventa en Colombia se dieron con altos niveles de impunidad, se otorgaron amnistías e indultos que supusieron perdón y olvido para crímenes graves, lo cual alimentó otras dinámicas sociales de violencia; y en el proceso con los paramilitares, aunque se construyó un marco jurídico transicional, la impunidad sigue siendo una de sus principales características. Por ello, los colombianos rechazan en el actual proceso de paz con las FARC la posibilidad de amnistías, indultos o rebaja de penas a los máximos responsables por los crímenes causados, constituyéndose en el principal desafío de un posible acuerdo.

La sociedad colombiana ha tenido un doble estándar en la aceptación del proceso de paz con los paramilitares y el actual con las FARC, siendo desfavorable para el último, en razón a que la narrativa oficial del conflicto ha estado más dirigida a condenar los crímenes de las guerrillas que la de los paramilitares, aunque ambos han recurrido de distintas maneras a la violencia contra los civiles. La resignificación de las AUC como fuerza antiinsurgente durante el gobierno del Presidente Álvaro Uribe contribuyó a aceptar los fines sin condenar los medios, esto se puede observar en las marchas de rechazo a uno y otro ejército en el año 2008. En aquella contra las FARC, la participación fue masiva, se habla incluso de seis millones de personas, contando ciudades de Colombia y varias del mundo; y mucho más reducida, alrededor de un millón de personas, la que se organizó contra los crímenes del Estado y de los paramilitares.
La atención integral a las víctimas supone también medidas de protección personal, de bienestar social, de atención médica y psicológica adecuada, de verdad, justicia y reparación, y como se señala para el caso del Perú, reparación enfocada no solo en superar la victimización individual, sino en equilibrar las disparidades sociales, proveyendo condiciones de ciudadanía integral para comunidades históricamente marginadas (Correa, 2013).

\section{El mediano plazo: reinserción y reconstrucción de comunidades}

En conflictos armados de larga duración y con degradación de los medios y métodos de la guerra, la victimización masiva es un desafío para el post-conflicto pues supone la atención integral a nivel individual, comunitario y social de víctimas directas e indirectas de la guerra. La atención psicosocial es un aspecto que en muchos procesos de DDR no son suficientemente atendidos, como en el caso de Colombia, siendo que "la reintegración social y psicosocial no puede ni debe estar desligada del proceso de reconstrucción postconflicto tanto para desmovilizados como para la comunidad" (Herrera \& González, 2013, p. 287).

La psicología social (Martín-Baró, 1990) es crítica del tratamiento enfocado solamente en la neurosis traumática o estrés postraumático ya que desde esta perspectiva el tratamiento singularizado encubre la realidad de la victimización producto del entorno de violencia sociopolítica y de la estructura social, y no sólo de la relación del sujeto particular con el hecho violento, que crea las condiciones para la re-victimización, siendo entonces necesario cambiar esas condiciones para que se dé efectivamente la recuperación individual y colectiva (Arévalo, 2010). 
La guerra entonces "cristaliza" relaciones sociales patológicas y deshumanizadoras, expresadas en a) la polarización social que se expresa a nivel comunitario e individual, sobre todo de las áreas geográficas más afectadas por la conflagración, b) el contexto de mentira institucionalizada que obliga a aquellos que no comparten los valores del régimen establecido a estrategias de negación y de separación de "las vivencias subjetivas y la vida social” y c) la militarización de la vida social que "puede ocasionar progresivamente una militarización de la mente" (Martín-Baró, 1990, pp. 11-12), legitimando y generalizando el uso de la fuerza y la violencia en las relaciones cotidianas.

Aunque no se trata sólo del régimen establecido, es decir la parte gubernamental como lo anota Martín-Baro, en la guerra quien domina un territorio se constituye, de facto, en el poder soberano; por lo tanto estas características que el autor expone sobre todo de la violencia vertical ilegitima, es decir desde el gobierno constituido y refutado por la confrontación bélica, también están presentes en las zonas que controlan los otros poderes de facto en la sociedad como guerrillas, señores de la guerra, o fuerzas paramilitares.

Un reto del mediano plazo entonces es cambiar actitudes, prácticas y mecanismos sociales que incentivan las relaciones adversariales violentas, es decir el recurso constante a posiciones de amigo-enemigo en la vida cotidiana o política. La transición hacia escenarios y prácticas más democráticas implica entonces incentivar nuevas formas de tramitar los conflictos en la sociedad, con lo cual se hace necesario programas masivos y permanentes de educación para la paz y la democracia, en todos los niveles del sistema educativo, y también en los medios de comunicación de masas que incentiven los valores de respeto por la diferencia y la diversidad (política, religiosa, ideológica, sexual, étnica, etc).

También son necesarias reformas del aparato de justicia que permitan la creación y funcionamiento de mecanismos alternativos de solución de controversias, más allá de los tribunales y grandes cortes; y sobre todo el fortalecimiento de las instituciones judiciales para garantizar la aplicación de la ley a quienes recurren a la fuerza y la criminalidad. La impunidad, como lo muestra el caso de Colombia, es un poderoso incentivo para la violencia y en consecuencia para la persistencia de la victimización.

La reconstrucción de comunidades destruidas por la guerra, en los casos que eso es posible, también es una tarea necesaria para la estabilización de las sociedades durante el post-conflicto. Esto implica medidas gubernamentales de tipo administrativo y judicial, que permitan la recuperación y reasignación de tierras para las familias o individuos desplazados o refugiados por la guerra, el desarrollo de proyectos productivos y medidas de apoyo gubernamental (subsidios, prestamos, descuentos impositivos) que garanticen el sostenimiento económico, al igual que la instalación de instituciones de bienestar social (gobiernos locales, escuelas, hospitales, etc.). En los casos en que los ejércitos han hecho uso de material de guerra no convencional, es necesario implementar programas de limpieza de las zonas para evitar nuevas víctimas, por ejemplo, en Colombia será necesario un programa masivo de desminado, como el que ya se propuso en La Habana.

La victimización femenina es una consecuencia recurrente de la guerra por la violencia sexual que ejercen los combatientes hacia ellas; la prostitución forzada, los embarazos no deseados, las enfermedades de transmi- 
sión sexual, el abandono familiar, el asesinato de esposos, padres o hermanos cuidadores, el reclutamiento forzado de niños y adolescentes, la pérdida de medios de subsistencia, entre otros, obliga a establecer en el postconflicto programas de atención específica para mujeres, tanto para superar la condición de victimización como para reconstruir las comunidades afectadas.

Los hombres van a la guerra y vuelven de ella a espacios femeninos de acogida que es necesario proteger del estrés de la violencia armada, la violencia doméstica, y la fragilidad económica; de igual manera, es preciso crear mecanismos de acompañamiento psicosocial que empoderen a las mujeres, las protejan y que a la vez contribuyan a la reinserción familiar y social de los hombres excombatientes de su entorno. La omnipresencia de los actores armados y de la violencia en la guerra afecta los comportamientos individuales y colectivos, perturbando por ejemplo las percepciones de lo que es correcto e incorrecto, desplazando el juicio al ejercicio de la fuerza y a la capacidad de imponerse sobre el más débil, o a la justicia por cuenta propia, en un continuo que va desde los ámbitos de la guerra hasta los espacios cotidianos como la familia o la escuela, y en los que niños y mujeres son muy vulnerables.

Esto mismo limita la autonomía, personal y colectiva, ya que la capacidad de acción, o reacción, se subordina a las percepciones sobre los combatientes; su ideología, sus prácticas, sus prejuicios, en últimas, al miedo a ser objeto de la violencia, lo que genera desconfianza hacia el otro, hacia la propia capacidad para escapar de los efectos de la guerra, lo cual puede llevar al aislamiento individual y familiar, a la ruptura de los lazos comunitarios y con ello al debilitamiento de los referentes identitarios. La identidad individual y colectiva se afecta, o se rompe, por efectos de la desestructuración de los vínculos emocionales con el entorno, las comunidades próximas (familia, barrio, vereda, pueblo) o las adscripciones políticas, étnicas, religiosas o culturales que la violencia provoca, afectando gravemente, la psiquis y la sociabilidad de los afectados, en tanto provoca la ruptura de creencias, valores, prácticas, formas y estilos de vida.

El asesinato, la desaparición, los castigos colectivos, la tortura, el genocidio, las violaciones o el desplazamiento masivo de personas, entre otros, como armas de guerra cuyos objetivos van desde el debilitamiento de las bases sociales y políticas del "enemigo", la ventaja militar, o el provecho económico, provocan un entorno de amedrentamiento, impotencia u horror que paraliza la acción colectiva o la reacción ante la agresión, y si además el verdugo es el gobierno que se supone legítimo, entonces la afectación se incrementa pues la agresión proviene de quien en principio se espera protección, generando en las personas una incoherencia en términos de que quienes deberían proteger se convierten en victimarios. Es necesario recuperar esta dimensión de confianza hacia los otros y hacia las instituciones para recuperar individuos, comunidades y tejido social.

La mayoría de conflictos, especialmente aquellos que se dan por incompatibilidades en el tipo de gobierno y cuyo objetivo es modificar la composición de este o reemplazarlo totalmente, así como los que disputan territorio, bien por el reclamo de más autonomía o incluso independencia, generalmente se sellan con medidas de reparto del poder, o de secesión territorial, validadas por mecanismos electorales (Högbladh, 2012). La implementación de esos acuerdos para compartir territorio o poder político del nivel nacional o local, es una actividad de construcción 
de paz que implica facilitar la participación política de los excombatientes, la conformación de partidos políticos y garantías de transparencia electoral. Esto significa el apoyo para estructurar partidos, financiar campañas, garantizar transparencia, acceder a medios de comunicación masiva, brindar seguridad a los nuevos actores políticos, y medidas para proteger también de la hostilidad o la violencia a los electores, entre otros.

El acompañamiento y la verificación internacional puede ser un mecanismo para brindar garantías de elecciones transparentes, apoyar los primeros momentos de la estabilización mediante financiación, transferencia de capacidades institucionales, capacitación de funcionarios públicos y comunidades, entre otros. La cooperación sur-sur o a través de esquemas de gobernanza regional, puede ser un camino cuando la sombra de potencias hegemónicas ha sido un factor determinante en el desarrollo del conflicto.

\section{El largo plazo: Cambios de prácticas y modelos}

La implementación de los acuerdos de paz propiamente dichos significan cambios profundos en las estructuras legales, el reparto de competencias, territorio y poder entre niveles subnacionales, la instauración de gobiernos provisionales, el ajuste de instituciones y mecanismos de gobernabilidad, o reformas a las fuerzas armadas, a fin de superar las incompatibilidades que generaron la disputa inicial y prevenir el surgimiento de nuevos conflictos o el reinicio de las hostilidades por incumplimiento de las partes ${ }^{9}$. Se analizarán aquellas medidas de largo plazo que según el Uppsala Conflict

9 De acuerdo con el UCDP en 8 conflictos de los 216 acuerdos de paz analizados, la violencia resurgió en Angola (1994), Cambodia (1991), Guinea Bissau (1998), Costa de Marfil (2004), Ruanda (1993), Sierra Leona (1996), Uganda (1985) y Chad (1979) (Högbladh, 2012).
Data Program (UCDP) son más recurrentes en los 216 acuerdos de paz que ha documentado, ampliando algunos conceptos con los aportes del caso colombiano. Así, nos referiremos a disposiciones políticas, militares (Högbladh, 2012) y a la construcción de Estado.

\section{Disposiciones Políticas}

Son medidas de cambio para compartir el poder o el territorio tras la firma de acuerdos de paz, y se refieren sobre todo a mecanismos de integración en el gobierno, instalación de gobiernos interinos, partidos políticos, elecciones, democratización de medios de comunicación, reforzamiento de la separación de poderes, ordenamiento territorial y estatuto de gobiernos subnacionales, independencia del poder judicial, legitimación de autoridades de control y de instituciones electorales.

Incluye también mecanismos de desarrollo social y económico que permitan arraigar los valores de la democracia en la sociedad, como garantías para el disfrute de derechos económicos, sociales y culturales, disminución de patrones de inequidad social, políticas públicas de bienestar social y el fortalecimiento de las instituciones públicas que proveen esos servicios. Colombia muestra cómo altos niveles de inequidad social, debilidad institucional, criminalidad y guerra, pueden atascar a las sociedades en la violencia.

La profundización de la democracia para buscar estabilidad y legitimidad también requiere de la ampliación de mecanismos de participación y representación de grupos poblaciones excluidos como comunidades indígenas, afrodescendientes, migrantes extranjeros, grupos de organizaciones que defienden los derechos de las mujeres, de los homosexuales $u$ otros sectores poblacionales. 
En Colombia, tras los acuerdos de paz de los años noventa, la Constitución de 1991 incorporó por primera vez al sistema político a exguerrilleros y grupos minoritarios. Además de ampliar la democracia, también reformó el modelo de desarrollo, imponiendo la economía neoliberal, de moda en América Latina por aquellos tiempos.

Uno de los aspectos más importantes de las medidas de cambio para la paz de largo plazo en los post-conflictos está en el nivel individual, incentivar prácticas culturales (actitudes, emociones y comportamientos) de democracia a todos los niveles (familiar, laboral, político), arraigada en valores colectivos, y no sólo en adscripciones tribales, religiosas, políticas, sexuales, o cualquier otro tipo de segmentación política que profundice las diferencias. Las sociedades en post-conflicto asumen tres retos esenciales para la democracia, "reintegración política, reconciliación política y participación ciudadana" (Ugarriza, 2013, p. 152).

\section{Disposiciones militares y de seguridad}

Estas hacen referencia a las medidas de cese al fuego y la verificación del mismo, la integración de excombatientes rebeldes en los ejércitos nacionales, o la reducción de efectivos tras el fin del conflicto, reformas institucionales a los aparatos de seguridad y defensa nacional, ajustes a los presupuestos públicos y reconversión del gasto militar, la legislación de reclutamiento forzado, y medidas para mantener el DDR, entre otros. Los casos de Centro América ilustran la reducción sustancial que se da en los efectivos militares, tras la firma de acuerdos de paz que finalizan conflictos internos. En Nicaragua se pasó de 100 mil a 15 mil hombres, en El Salvador de 63 mil en 1991 a 31 mil en 1993, y a 15 mil en 2003, y en Guatemala de 60 mil a 16.500 en 2005. También en los tres casos se disminuyó el presupuesto de defensa (López, 2014).

El desafío para Colombia será la reducción de su capacidad sin afectar la seguridad nacional, ya que hoy cuenta con 428.000 hombres en las Fuerzas Armadas, (265.707 de las Fuerzas Militares y 163.152 de la Policía) y dispone de un presupuesto de $\$ 21.5$ billones. También tendrá que modificar sus estrategias de seguridad nacional, y las estructuras institucionales del Ministerio de Defensa, el Ejército o la Policía Nacional, y dirigirlas a medidas de seguridad ciudadana, que en muchos casos recaen especialmente en los aparatos policiales para controlar mafias transnacionales y crimen urbano, que como en los casos de El Salvador y Guatemala, pueden incrementarse en el período de post-conflicto.

El control civil del poder militar a través de mecanismos democráticos de rendición de cuentas, investigación y castigo de la corrupción, sanción por la justicia civil de las violaciones de derechos humanos, y sobre todo la "desmilitarización" de la sociedad, con mecanismos que limiten la deliberación política de los militares para prevenir escenarios de violencia partidista, así como programas públicos que impulsen cambios de mentalidad al interior de las fuerzas armadas para aceptar al enemigo como compañero de armas o como contendor político en los debates electorales, serán medidas igualmente necesarias que deberán adoptarse.

\section{Construcción de Estado}

Además de las disposiciones que señala Högbladh (2012), es decir medidas para el control de territorios, cambios de estatuto para perseguir mayor autonomía, diseños fe- 
derales, procesos de independencia, reparto de poder y autonomía local de los gobiernos, desarrollo regional, establecimiento de límites, entre otros, el caso de Colombia muestra cómo la construcción de paz en muchos post-conflictos está asociada también a la construcción de Estado. Además del fortalecimiento y democratización de las instituciones a todos los niveles es necesario garantizar presencia, no sólo militar sino también a través de derechos económicos, sociales y culturales, en las zonas donde ha sido insuficiente o nunca ha estado.

La provisión de servicios sociales básicos como educación, salud, bienestar, seguridad, justicia, así como la construcción de infraestructura necesaria para el desarrollo de las regiones más apartadas de los centros urbanos principales y la instalación de instituciones y funcionarios públicos, junto con incentivos y mecanismos de impulso a la economía legal, son parte del proceso de estabilización de las sociedades que han vivido la guerra.

Los nichos de ilegalidad que permiten zonas alejadas de los ejes del poder político o económico crean incentivos para el surgimiento de poderes de facto, dinámicas de crimen organizado, uso de la violencia como recurso estratégico y estimulan las lealtades particulares, casi siempre de tipo mafioso, en detrimento de una ética colectiva, con lo cual se hace difícil garantizar los procesos de DDR, siendo posible entonces el rearme o la organización de nuevos ejércitos dispuestos a continuar con la guerra. Se busca que el Estado, como representación de lo colectivo, recupere el monopolio del uso de la fuerza, garantice la primacía del derecho, desincentive la justicia por cuenta propia y el recurso constante a la violencia para alcanzar objetivos privados o públicos.

\section{Conclusión}

La finalización de conflictos armados internos mediante acuerdos de paz es un laboratorio para entender la manera como se da el cambio cultural e institucional en las sociedades. El proceso de dejar atrás dinámicas de violencia permanente para construir escenarios democráticos, reconstruir comunidades y relaciones sociales, así como transformar prácticas para garantizar que no haya un rearme de combatientes y se retorne a la guerra como camino para solucionar las diferencias, propone desafíos que deben asumir las sociedades en el corto, mediano y largo plazo, durante la etapa de post-conflicto.

La reincorporación política de los combatientes, la reconciliación de la sociedad, los ejercicios de verdad, memoria y justicia para reconocer a las víctimas, responsabilizar a los victimarios y sanar las heridas de la guerra, son el comienzo de un largo, complejo y a veces doloroso proceso de transformación, que va de la dimensión estructural y colectiva a la individual, de decisiones de alta política a transformaciones personales acerca de la manera como se entiende y se tramita la diferencia y el conflicto en las sociedades. E objetivo es instalar en las mentes, en las actitudes y en las prácticas, el reconocimiento de la diversidad en todas sus manifestaciones, el respeto cardinal a la vida del otro y a los acuerdos de la sociedad.

Pasar de relaciones adversariales violentas propias de la guerra a la rivalidad política de la democracia, supone construir primero una imagen común de lo que debe ser la sociedad, un marco mental inicial para la paz. En este proceso es esencial que los líderes políticos impulsen narraciones de reconciliación, la difundan a través de los medios de comunicación masiva, los aparatos de educación, ade- 
más que sea apoyada por los colaboradores internacionales, a fin de garantizar legitimidad, y condiciones para transformar las mentes preparadas para la guerra y la confrontación.

Una vez acordada la paz, las medidas de cese al fuego, de DDR y de justicia transicional tienen que ejecutarse para atender a las poblaciones más afectadas con la guerra, victimas y combatientes, y prevenir con ello el rearme o la revictimización. Finalmente vendrán las transformaciones estructurales que implican reformas políticas, económicas, judiciales, culturales y sociales para tratar las disputas que originaron la violencia y prevenir nuevas divergencias esenciales. Si hay voluntad para dejar atrás la guerra, las "estirpes condenadas a cien años de soledad" sí pueden tener una segunda oportunidad sobre la tierra.

\section{Referencias bibliográficas}

- Arendt, H. (2006). Sobre la violencia. Madrid, España: Alianza Editorial.

- Arévalo, L. (2010). Atención y reparación psicosocial en contextos de violencia sociopolítica: una mirada reflexiva. Revista de Estudios Sociales, (36), 29-39.

- Arjona, A., \& Kalyvas, S. (2005). Paramilitarismo: una perspectiva teórica. En A. Rangel, El poder paramilitar (pp. 25-40). Bogotá, Colombia: Planeta.

- Centro Nacional de Memoria Histórica. (2013). jBasta Ya! Colombia: Memorias de guerra y dignidad. Resumen. Bogotá, Colombia: Pro-Off Set.

- Cheyanne, \& Rogers, M. (2006). Designing for Results: Integrating Monitoring and Evaluation in Conflict Transformation Programs. Recuperado de https://goo.gl/2TxwBz

- Correa, C. (2013). Reparative Justice. Reparations in Peru. New York: International Center for Transitional Justice.

- Echandía, C. (2013). Narcotráfico: Génesis de los paramilitares y herencia de las bandas criminales. Bogotá, Colombia: Fundación Ideas para la Paz.

- El Tiempo. (2012). Las cifras de los 10 años de desmovilización. El Tiempo.com Recuperado de http://goo.gl/bwHiqR

- El Tiempo. (4 de Febrero de 2014). 'Hay poca tierra devuelta y muchos muertos': líderes de restitución. El Tiempo.com Recuperado de http://goo. $\mathrm{gl} / \mathrm{lzUJhu}$

- Galula, D. (1964). Counter-Insurgency Warfare. Theory and Practice. New York: Frederick A. Praeger, Publisher.

- Gallón, G. (2014). Ocho años de "Justicia y Paz": un balance con más sombras que luces. Recuperado de http://goo.gl/nvHgf9

- García-Durán, M. (2006). Paz en el territorio:dinámica de expansión geográfica del accionar colectivo por la paz en colombia 1978-2003. Territorios, (15), 20-49.

- Herrera, D., \& González, P. (2013). Estado del arte del DDR en Colombia frente a los estándares internacionales en DDR (IDDRS). Colombia Internacional, (77), 272-302.

- Högbladh, S. (2012). Peace Agreements 1975-2011. States in Armed Conflict 2011. Recuperado de http://goo.gl/c0G1Ni

- ICTJ. (2011). Transitional Justive in the United Nations Human Rights Council. Recuperado de https://goo.gl/GHI49j

- INDEPAZ. (2014). El Cagúan. Recuperado de http://goo.gl/pXI9Nt

- Kalyvas, S. N. (2006). La lógica de la violencia en la guerra civil. Madrid, España: Akal.

- Kornfeld, E. L. (1991). Psicologia de la amenaza politica y el miedo. Recuperado de http://goo.gl/c0TN6B

- Lekha, C., Martin-Ortega, O., \& Herman, J. (2010). War, Confict and Human Rights. Theory and practice. London and New York: Routledge.

- López, M. U. (2014). Fuerzas Armadas, postconflicto y seguridad ciudadana. Bogotá, Colombia: Corporación Viva la Ciudadanía.

- Martín-Baró, I. (1990). Psicología social de la guerra: trauma y terapia. San Salvador: UCA Editores.

- Martin-Baró, I. (2003). Poder, ideología y violencia. Madrid, España: Trotta.

- Martínez, E., \& Arévalo, L. (2009). Ideas para la comprensión de las violencias. En C. Vínculos, Acompañamiento psicosocial en contextos de violencia sociopolítica (pp. 11-26). Bogotá, Colombia: Antropos.

- Mesa de Conversaciones. (2012). Acuerdo General Para la Terminación del Conflicto y la construcción de una paz estable y duradera. Recuperado de https://goo.gl/wZFOfp

- Nussio, E. (2013). Desarme, desmovilización y reintegración de excombatientes: políticas y actores del postconflicto. Colombia Internacional, (77), 8-16.

- Patiño, O., Grabe, V., \& García-Durán, M. (2009). El camino del M-19 de la lucha armada a la democracia: una búsqueda de cómo hacer política en sintonía con el país. En M. García-Duran, De la insurgencia a la democracia. Estudios de caso. Colombia, Sudáfrica, Irlanda del Norte, Acheh, Nepal, Sri Lanka (pp. 43-106). Bogotá, Colombia: Cinep.

- Sánchez, G. (2013). Discurso de Gonzalo Sánchez- ¡Basta Ya! Recuperado de http://goo.gl/IQrcc7

- Schmitt, C. (1998). El concepto de lo político. Madrid, España: Alianza.

- Semelin, J. (2002). Violencias extremas: ¿es posible comprender? Revista Internacional de Ciencias Sociales. (174), 4.

- Séneca. L. A. (2015). Tratados morales. Recuperado de http://goo.gl/3CNb1C

- Taber, R. (1970). La guerra de la pulga. Guerilla y contraguerrilla. México: Biblioteca Era Testimonio.

- Ugarriza, J. E. (2013). La dimensión política del postconflicto: discusiones conceptuales y avances empíricos. Colombia Internacional, (77), 141-176.

- UNODC. (2013). Global study on homicide 2013. Vienna: United Nations Office on Drugs and Crime.

- Uppsala University. Department of Peace and Conflict Research. (2014). The Uppsala Conflict Data Program. Recuperado de http://goo.gl/7xnVrd

- USAID, Americas Barometer, VanderBilt University, Universidad de los Andes, Observatorio de la Democracia. (2013). ¿QUÉ PIENSAN LOS COLOMBIANOS DEL PROCESO DE PAZ? Una mirada desde el Barómetro de las Américas. Bogotá, Colombia: Uniandes. 